International Journal of English Language Studies (IJELS)

ISSN: 2707-7578

DOI: 10.32996/ijels

Website: https://al-kindipublisher.com/index.php/ijels

\title{
Prediction Chart: A Tool in Enhancing Reading Comprehension
}

Jesum M. Pitogo

Senior High School Teacher II, Department of Education-Mandaue City, Cebu, Philippines

Corresponding Author: Jesum M. Pitogo, E-mail: jesum.pitogo@deped.gov.ph

\section{ARTICLE INFORMATION}

Received: December 02, 2020

Accepted: February 17, 2021

Volume: 3

Issue: 2

DOI: 10.32996/ijels.2021.3.2.3

\section{KEYWORDS}

Prediction chart, reading

comprehension, quasi-

experimental, reading strategy,

pretest performances, posttest

performances

\section{ABSTRACT}

Reading is considered as one of the essential components of the macro-skills in Linguistics and it is one of the various language skills that a learner must possess. It is an acquired skill for which the individual has the unique ability to pursue meaning from the text. Given this definition, the main purpose therefore of reading is comprehension, and without it, reading does not take place. The study assessed the effectiveness of prediction chart in enhancing the reading comprehension of Grade 12 students of University of Cebu Lapu-lapu Mandaue, Mandaue City, Cebu, S.Y. 20192020. The study employed a quasi-experimental design. The research subjects of the study were 46 Grade 12 students. These subjects were grouped into two heterogeneous groups: the control group and experimental group. The experimental group were the only subjects exposed to the use of prediction chart, using the interventional material "My Father Goes to Court" by Carlos Bulosan, while the control group were exposed to the traditional classroom instruction using the same intervention material. A researcher-made questionnaire was utilized to assess the effectiveness of prediction chart. Based on the study results, the control group's pretest performance has a significant difference from their posttest performance. This implies that the use of the traditional classroom instruction or pure lecture does not enhance the reading comprehension of the control group. In contrary, pretest performances of experimental group significantly differ from their posttest performances. Thus, the study concluded that the use of prediction chart in enhancing the reading comprehension of grade 12 students is effective. With this premise, the students can develop higher order thinking skills (HOTS) and camaraderie while learning as they step higher on their level of education.

\section{Introduction}

Reading is considered as one of the essential components of the macro-skills in Linguistics and it is one of the various language skills that a learner must possess It is an acquired skill for which the individual has the unique ability to pursue meaning from the text. Given this definition, the main purpose therefore of reading is comprehension, and without it, reading does not take place. Besides, comprehension is characterized as a cognitive process of building understanding that is interconnected with each other from the written material.

However, comprehension is becoming a learning problem among learners. In the Philippines, the 2009 National Achievement Test (NAT) results revealed below mastery level performance of the test takers. One of the compelling reasons is their poor reading comprehension. The head of the DepEd's Bureau of Elementary Education, Dr. Yolanda Quijano said that reading problems are the primary factor for the low performance of some learners in the NAT. Her observation is indeed worrying. Therefore, if the reading comprehension of a student is low, his or her success in other subjects is likely to be affected (Philippine Star, 2010).

K C AL-KINDI CENTER $\mathbf{R}$ D FOR RESEARCH AND DEVELOPMENT Your gateway to world-class research

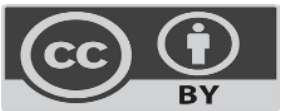

Published by Al-Kindi Center for Research and Development. Copyright (c) the author(s). This open access article is distributed under a Creative Commons Attribution (CC-BY) 4.0 license 
To address this alarming problem, teachers must develop the ability of the students to understand the reading material. One of the twenty first century skills that a student must possess is critical thinking. Thus, for them to be a critical thinker and foster reading comprehension, they should learn the ability to predict because making predictions in reading is vital.

Moreover, for more than three years, the researcher has been teaching literature subjects to college and senior high school students. The purpose of Literature is to engage students in the appreciation of its different genres, components, and structure and make a critical study of the various literary masterpieces. However, the researcher strongly believes that a learner cannot appreciate the beauty of literature nor can create a critical study if they have difficulty in comprehending the texts. Based on the actual observations of the researcher, he has noticed that whenever he introduces twenty-first century short stories to the class, the students find it difficult and challenging in understanding the story. This personal experience by the researcher is one of the compelling grounds why such study is viewed important. Thus, comes the interest of the researcher to conduct this study to assess the effectiveness of prediction chart in enhancing the reading comprehension of the senior high school students.

\section{Theoretical Background}

This research study is mainly anchored on schemata theory by Frederic Bartlett. The schema theory of Frederic Bartlett believes that a person has the unique ability to connect new information to the older knowledge stored in the memory. Schema can be viewed as ordered awareness of the context, which leads us to anticipate or foresee aspects of our discourse understanding. It is a kind of structure, or strategy, or script. These are created by experiencing the world with individuals, artifacts, and events (Ajideh, 2003).

Therefore, it is believed that a student can connect new information to the older knowledge stored in the memory. Thus, this concept can be applied when students give their initial predictions of the story based on their personal experiences and prior knowledge. Furthermore, most discussions of schema theory provide logical evidence of the great importance of one's background knowledge or schema in reading comprehension and it becomes an important variable in the conduct of this study.

The second theory that supports schemata theory is the observational learning theory of Albert Bandura. This theory focuses on analyzing and modeling another person's actions, attitudes, or emotional responses and modeling them. It is generally believed that the observer will copy the model. It is also emphasized that individuals should simply learn from the behavior rather than imitate it. This learning theory is a major component of Bandura's social learning theory. It also stressed that four conditions were important in any form of observing and modeling actions: concentration, conservation, replication, and determination (Stone, 2017).

According to Stone (2017), Attention or focus is the first requirement for observational learning. If a person is going to learn something from a model, he or she must pay attention to it and the conduct it demonstrates, and there are many situations that may influence the attention of the observer. The second criterion for observational learning is to be able to remember the behavior that was witnessed. There is a less than probable chance that if an individual does not remember the behavior, they will imitate it. Moreover, the third condition is replication or reproduction. This criterion includes the physical and mental ability of the person to copy the acts he or she has observed. Lastly, determination or motivation is the fourth condition. This simply means that if the individual does not have a motive to adopt the behavior, the lack of motivation can be overcome by no amount of focus, conservation, or replication. Thus, the most significant aspect of observational learning is motivation.

Thus, this theory gives a logical explanation that students may learn by merely looking and observing the different illustrations presented by the teacher. With this, they may be able to give accurate predictions and help them comprehend the story easily.

The third theory that supports schemata theory is the nine events of instruction by Robert Gagne. The teaching events include nine tasks, according to Wager, Gagne \& Briggs (1992), namely: attracting attention, reminding the students of the target or goal, reviewing the prior learning or lessons, introducing the stimuli, giving pedagogical scaffolds, evoking the outcomes, giving input, evaluating the productivity or performance, and improving transition and retention.

The first step is to attract interest, ensuring that students are prepared to understand and engage in various learning activities by providing an opportunity to attract their focus. The second stage is reminding the learner of the goal. It is believed that the target or goal must be provided before instruction begins. The third step is to promote reminders of the previously learned concepts or topics, helping the learners to remember the recent concepts by comparing it to what they already understand or have already encountered. Presenting the stimulus is the fourth step. To provide more effective, efficient teaching, it is the use of techniques to present and cue lesson material. The fifth step is providing learning guidance. This can be done by providing instructional scaffold to the learner as needed. The sixth step is eliciting performance, this can be achieved by asking learners to clarify or describe information and to provide their answers with more complexity. The seventh step is providing feedback, these are the constructive comments, suggestions, and recommendations on the student's performances. The next step is assessing 
performance; this can be achieved by utilizing appropriate assessment tools. Enhancing retention and transition is the last step. They must internalize new information to help learners gain expertise. (Wager, Gagne \& Briggs, 1992).

To note, in teaching reading with the use of prediction chart, teachers must utilize appropriate instructional materials and facilitate the reading activity so that students can comprehend the story and they must follow a systematic procedure.

The above theories are valid based on the formulation of the problem and implications of findings. With this premise, the prediction chart as strategy in reading is supported by the three theories mentioned above.

\section{Related Literature and Related Studies}

There are different engaging reading strategies that can be utilized in teaching a short story to the class. Thus, a teacher must utilize different strategies to cater the interests of the students. As cited by Anderson (2008), teacher should utilize effective reading strategy so that the learners can increase their comprehension level.

One of the reading strategies that could be helpful for the learner is through the use of prediction strategy. Before reading, a reader may give initially some predictions of a certain story. Constructing insightful predictions has to do with creating assertions based on the title, images, or charts about what the text is about and then reading verify perceptions. Preparing students to utilize this idea would guarantee their constructive engagement and making it simpler to practice reading (Nuttall, 1982).

Furthermore, according to Bailey (2015), prediction strategy enables students to use details such as descriptions, headings, illustrations, and diagrams from the written text and their own actual interactions in order to anticipate what they will read and what will happen in the plot.

This idea is supported by Durkin (1993) who said that comprehension can also be improved by building on students' prior knowledge or schema. Moreover, a prediction strategy reads the text to find out what happens to trigger context information, peeking or previewing and overlooking or summarizing. This reading technique helps students to produce ideas or findings about how the personalities or characters should behave or respond in accordance to the context, circumstance, or events in the plot. (Thomas-Fair, 2005).

According to Magliano, Baggett, Johnson and Graesser (1993), the prediction strategy is believed to include thinking about what could come next in the text. Efficient readers submit it. Before beginning to read, they used photographs, headings, and text as well as personal knowledge to make predictions. Therefore, forecasting includes looking ahead when reading and anticipating data and events in the text.

Likewise, Gaither (2011) believes that it also allows learners to consider what will happen based on the text, the author, and context information, in other words, it lets students evoke their interest, trigger their previous knowledge, or pre-teach vocabulary or concepts that might be difficult. It is also seen as being used in reading tasks. Predicting, in this sense, allows learners to use the text to decide what will happen next. With help from the text, readers confirm or reject predictions (Test Wise Word Association, 2006).

Apparently, predictions are not gullible guesses. They include drawing conclusions, using data in the text and previous information to predict what will happen next. According to Roit (2017), students need to learn to do the following to make thoughtful predictions: find hints in the text and one's background information to support a prediction; determine when to construct a prediction based on the other point in a plot; validate predictions during and after reading; make and analyze alternative predictions; and review predictions and thinking about whether they were confirmed or tested or were not.

In addition, prediction strategy utilizes a prediction chart so that the readers can track their permanent record of what are they thinking before, during, and after reading a short story that leads to understanding the text. With this premise, the students can track their predictions as the story progresses (Raudenbush, 2019). Moreover, prediction charts offer structured opportunities for students to predict what is going to happen in a story and equate their predictions with actual events. As the story progresses, predictions generally become more accurate since students recognize clues and combine their background knowledge with what has already occurred. For primary students, a prediction chart needs to be developed under the teacher's guidance. More able readers can develop it individually or in a small group (Weingarten, 2002).

On the other hand, there are conducted research which are relevant to the efficacy of prediction strategy in improving the reading comprehension of learners. Thus, Research has shown that prediction techniques boost the aggregate or global comprehension of a story (Thomas-Fair, 2005). 
In today's generation, students are visual learners, and they make use of different graphic organizers so that they can visualize their ideas properly. According to Lumontad (2014), the use of concept maps is an efficient teaching strategy which develops their structural thinking skills. Thus, concept mapping is proven to be helpful in improving the reading comprehension skills of the students. Through concept mapping, the student's analytical, structural, and creative skills would be gradually enhanced making them better readers.

Likewise, according to Wulandari et al. (2017), after the students were taught in terms of descriptive texts through prediction strategy, the learner's reading comprehension significantly improves. In fact, the outcome of this research study showed that most of the students felt comfortable and they agreed that this method is successful in improving their understanding of the descriptive texts.

Moreover, according to the study conducted by Quế (2012), the test results indicate that predicting strategy has strengthened the understanding of the students' reading ability. In finding the subject of the text, answering the detailed questions with the aid of the image, and anticipating the upcoming details from the textual structure, the students were significantly better. Although the teaching of the predicting strategy has significantly raised the awareness of the students of these reading strategies and allowed them to make use of these strategies in reading, the difference is not important because understanding of reading is affected not only by strategies, but also by other factors such as text and vocabulary of the reader as well as their stored knowledge. Furthermore, predicting techniques are just a fraction of the strategies for language learning.

This reading strategy is also beneficial to the school children. According to Thomas-Fair (2005), This approach has other advantages, such as supporting children who want to use the story's vocabulary in their journal entries. Another advantage was that the kids were highly encouraged to use their imaginative ability for spelling. The overall advantage of this approach was that each time the technique was utilized, the children became more and more inspired to listen and provide their own independent discussion of the plot, the characters and their events. When engaging in center time at the reading center, they also modeled the technique. This method is one that is easy but effective. It allows for optimum involvement and a continuous flow of communication about the story from all members of the community. Research has also found that techniques involving prediction improve a story's overall or global comprehension.

Furthermore, the utilization of the three popular reading strategies (scanning, skimming, and predicting) is a rewarding process to direct students in the ninth grade along the path of independence, specifically in their cognitive aspects and making their school assignments, decision-making, and fostering encouragement. These techniques also helped the learners to understand the reality that they were creators of their personal possibilities and skills. As the learners undergo these processes, they became more open-minded and thoughtful on how to use and apply reading techniques for productive reading and fostering their independence. In addition, their reading abilities have been improved due to the successful use of reading techniques (Izquierdo \& Jiménez, 2014).

The cited studies give a conclusive idea that reading is very much essential to the lives of the learners and reading comprehension is vital. Thus, the results of the above studies confirm that prediction as a strategy plays a vital role in enhancing the reading comprehension of the learners. These findings provide convincing evidence for generalizing that it is significant to conduct a study about this reading strategy. However, there are existing gaps in the body of literature and the researcher wants to fill in these academic gaps. With this premise, the researcher wants to assess the effectiveness of this reading strategy among senior high school students because most of the research subjects in the foregoing research are school children and junior high school students. Likewise, the researcher also wants to determine if this reading strategy is applicable and effective in teaching Filipino short story. The study further gives an insight in venturing on the "Prediction Chart in Enhancing Reading Comprehension."

Therefore, the conduct of this study can be very beneficial to teachers who are handling literature subject. They may utilize the prediction chart during their lessons so that this can help stimulate the higher order thinking skills of their students. Thus, this reading strategy can also promote collaboration with their classmates and gain new experiences.

\section{Research Problem}

This study assessed the effectiveness of prediction chart in enhancing the reading comprehension of Grade 12 students, University of Cebu Lapu-lapu and Mandaue, Mandaue City, Cebu, S.Y. 2019-2020. The findings served as the basis for a proposed seminar-workshop for English teachers. 
Specifically, this study aimed to answer the following:

a. What are the pretest performances of the control and experimental groups?

b. What are the posttest performances of the control and experimental groups?

c. Is there a significant difference between the pretest performances of the control and experimental groups?

d. Is there a significant difference between the pretest and posttest performances of the control and experimental groups?

e. Is there a significant difference between the posttest performances of the control and experimental groups?

f. Based on the findings, what action plan would be proposed?

\section{Methodology}

The study assessed the effectiveness of prediction chart in enhancing the reading comprehension of Grade 12 students at University of Cebu Lapu-lapu Mandaue, Mandaue City, Cebu, S.Y. 2019-2020. The study employed a quasi-experimental design. A researcher-made questionnaire was utilized to assess the effectiveness of prediction chart with a Cronbach's Alpha of .845. Thus, this instrument is valid in the conduct of the study.

To obtain the data, a permission letter to conduct the research study was submitted to the principal of the senior high school department. Upon the approval of the letter of permission, the study was conducted. The class of ST12P2 from Science and Technology, Engineering and Mathematics (STEM) strand with forty-six (46) students were selected as the subjects of the study. Prior to the pre-test that was administered to the two groups, the same questionnaire was given to a group of students who were not directly involved in the study to identify the problems that may occur in the actual examination of the chosen research subjects. With this premise, the researcher can modify or change some questions that make no sense and to some test items that are irrelevant from the purpose of the study. Prior to the conduct of the study, the teacher discussed the elements of short story.

The research subjects were divided into two groups: the control group in Group 1 and the experimental group in Group 2. On the first session, the researcher gave a pretest on the short story entitled "The Legend of the Virgin's Jewel" of Nick Joaquin. The same pretest was given to the subjects of the two groups. However, the teacher introduced another short story entitled "My Father Goes to Court" of Carlos Bulosan to the experimental group for the intervention.

On the second session during the intervention, the experimental group was divided into eight groups. Each group was given with a prediction chart and the teacher explained the mechanics on how to use it. Then, the plot of the story was introduced to the students sequentially with the use of prediction chart.

The prediction chart was divided into three columns. The first column is for the different segments of the story so that the students would be guided on the chronological order of the story. The second column was intended for the prediction of the students. The last column was intended for what actually happened in the story. The teacher utilized different pictures, headings, photographs, and drawings that were all based on the story of Carlos Bulosan. The assigned reading was divided into segments that involved specific action taken by the character(s) in the story. Then, the students from each group together with their groupmates made a prediction as to what they thought would happen in each segment of the story prior to reading that particular segment. Then, they wrote their predictions in the chart.

After the students wrote all their predictions in the second column, they were asked to read the segments of the story. Then, students wrote down what actually happened in the story on the third column and compare it to their predictions. As the story progresses, predictions generally became more accurate since students recognized clues and combined their background knowledge with what had already occurred.

On the third session, the research subjects in the control group were given the traditional way in discussing the short story of Carlos Bulosan. After the whole story was presented, the teacher gave a posttest exam to the experimental and control groups with the same set of questions in the pretest. The data gathered were treated for tabulation, statistical analyses, and interpretation. The result served as basis for the proposed action plan. 


\section{Results and Discussion}

Control and Experimental Groups' Pretest Performance

Table 1. Control and Experimental Groups' Pretest Performance

\begin{tabular}{c|ccc|ccc}
\hline \multirow{2}{*}{$\begin{array}{c}\text { Range of } \\
\text { Scores }\end{array}$} & \multicolumn{3}{|c|}{$\begin{array}{c}\text { Control Group } \\
(n=23)\end{array}$} & \multicolumn{2}{c}{$\begin{array}{c}\text { Experimental Group } \\
(n=23)\end{array}$} \\
\cline { 2 - 6 } & $\begin{array}{c}\text { No. of } \\
\text { Students }\end{array}$ & $\%$ & Level of Performance & $\begin{array}{c}\text { No. of } \\
\text { Students }\end{array}$ & Level of \\
Performance
\end{tabular}

It is shown in table 1 that a greater majority (70\%) of the learners in the control group have a very good performance in the pretest as compared to the proportion of students in the experimental group (52\%). Moreover, a greater proportion (13\%) of students in the experimental group had a fair performance as compared to the control group (4\%).

Control and Experimental Groups' Posttest Performances

Table 2. Control and Experimental Groups Posttest Performances

\begin{tabular}{|c|c|c|c|c|c|c|}
\hline \multirow[t]{2}{*}{$\begin{array}{l}\text { Range of } \\
\text { Scores }\end{array}$} & \multicolumn{3}{|c|}{$\begin{array}{c}\text { Control Group } \\
(n=23)\end{array}$} & \multicolumn{3}{|c|}{$\begin{array}{c}\text { Experimental Group } \\
(n=23)\end{array}$} \\
\hline & $\begin{array}{c}\text { No. of } \\
\text { Students }\end{array}$ & $\%$ & $\begin{array}{c}\text { Level of } \\
\text { Performance }\end{array}$ & $\begin{array}{l}\text { No. of } \\
\text { Students }\end{array}$ & $\%$ & $\begin{array}{c}\text { Level of } \\
\text { Performance }\end{array}$ \\
\hline $25-30$ & & & & 2 & 9 & Excellent \\
\hline $19-24$ & 4 & 17 & Very Good & 12 & 52 & Very Good \\
\hline $13-18$ & 13 & 57 & Good & 9 & 39 & Good \\
\hline $7-12$ & 6 & 26 & Fair & & & \\
\hline $0-6$ & & & & & & \\
\hline
\end{tabular}

Comparing their posttest performances, table 2 shows the result that majority (52\%) of the learners of the experimental group has a very good performance in the posttest, while there are a good number (17\%) of the students in the control group who has a very good performance in the posttest. Majority (57\%) of the learners in the control group perform well.

Most learners performed well in the experimental group because they were taught on how to use their higher order thinking skills with the aid of prediction chart and they were able to collaborate and interact with their groupmates. Unlike with the students in control group, the teacher utilized the traditional or lecture method which is less interactive and teacher centered.

This can be explained by the idea of Nuttall (1982), who emphasized that training learners to utilize prediction as a reading skill would ensure their constructive engagement and making it simpler easier to practice reading. This idea is supported by ThomasFair (2005) who strongly believed that research has also found that techniques involving prediction improve a story's overall or global comprehension. 
Difference of the Pretest Performances

Table 3. Difference of the Pretest Performances of the Control and Experimental Groups

\begin{tabular}{lcccc}
\hline \multicolumn{1}{c}{ Variables } & Computed t & p-value & $\begin{array}{c}\text { Decision on } \\
\text { Ho }\end{array}$ & Interpretation \\
\hline $\begin{array}{l}\text { Pretest of the control and } \\
\text { experimental groups }\end{array}$ & 1.12 & .27 & Accept & $\begin{array}{c}\text { No significant } \\
\text { difference }\end{array}$ \\
\hline $5 \quad d f=41$ & & &
\end{tabular}

$\alpha=.0 \overline{5} d f=41$

Table 3 shows that the pretest performances of participants in the control group $(M=19.26, S D=3.28)$ does not significantly differ from the pretest performances of the experimental group $(M=18.00, S D=4.29), t(41)=1.12, p=.27$. It is very important that prior to the conduct of the study, the entry skills of the participants in the control and experimental groups are checked for matching. Since their pretest performances do not differ greatly, the two groups are balanced in terms of entry skills, so the prepost with control group is ideal for the quasi-experimental design.

Difference of the Pretest and Posttest Performances

Table 4. Difference of the Pretest and Posttest Performances of the Control and Experimental Groups

\begin{tabular}{lcccc}
\hline \multicolumn{1}{c}{ Variables } & Computed t & p-value & $\begin{array}{c}\text { Decision on } \\
\text { Ho }\end{array}$ & Interpretation \\
\hline $\begin{array}{l}\text { Pretest and Posttest of the } \\
\text { Control Group }\end{array}$ & 14.88 & $5.8 E-13$ & Accept & $\begin{array}{c}\text { No Significant } \\
\text { difference }\end{array}$ \\
$\begin{array}{l}\text { Pretest and Posttest of the } \\
\text { Experimental Group }\end{array}$ & -6.67 & $1.06 E-06$ & Reject & Significant difference \\
\hline $55 d f=22$ & & & &
\end{tabular}

Table 4 shows the results whether the use of prediction chart is effective in enhancing the reading comprehension of the respondents in both control and experimental groups.

It is observed that the pretest performance of the control group $(M=19.26, S D=3.28)$ does not significantly differ from their posttest performance $(M=14.69, S D=3.67), t(22)=14.88, p=5.8 E-13$. This means that the use of the traditional classroom instruction or pure lecture, does not enhance the reading comprehension of the control group, it lowers their posttest performances. This is contrary to the results of the pretest and posttest of the experimental group. It is found that the pretest performances of the experimental group $(M=18.00, S D=4.29)$ significantly differ from their posttest performances $(M=$ $19.74, S D=3.58), t(22)=-6.67, p=1.06 E-16$. This implies that the utilization of prediction chart enhances the reading comprehension of the experimental group.

The result of the pretest and posttest performances of the experimental group is supported by Wulandari et al. (2017), where it showed that after the students were taught in terms of descriptive texts through prediction strategy, there was a statistically significant increase in student's reading comprehension. 
Difference of the Posttest Performances

Table 5. Difference of the Posttest Performances of the Control and Experimental Groups

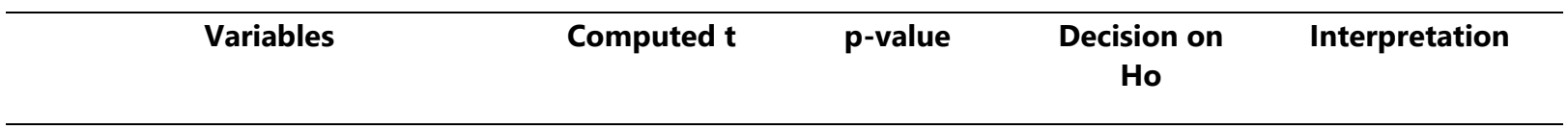

Posttest of the control and

experimental groups

$-4.76$

$2.25 E-05$

Reject

Significant

difference

$\alpha=.0 \overline{5} \quad d f=43$

Table 5 shows the comparison of the control and experimental groups' post-test results, and the results showed that the posttest gain of the control group and the experimental group significantly differ, $t(43)=-4.76, p=2.25 E-05$. This implies that the prediction chart does enhance the reading comprehension of the Grade 12 students.

As emphasized by Anderson (2008), teacher should utilize effective reading strategy so that the learners can increase their comprehension level. In this manner, prediction chart is an effective reading strategy that must be used inside the classroom and this would greatly benefit the teacher and the learners.

In addition, the findings of the study confirm that prediction chart was an effective reading strategy. Moreover, the findings conform to the study conducted by Quế (2012), the test results indicate that predicting strategy has strengthened the understanding of the students' reading ability. In finding the subject of the text, answering the detailed questions with the aid of the image, and anticipating the upcoming details from the textual structure, the students were significantly better.

\section{Conclusion}

One of the twenty-first century skills that a learner must possess is their ability to think critically. This skill can be enhanced through reading for it is considered as one of the essential components of the macro-skills in Linguistics. Hence, this study assessed the effectiveness of prediction chart in enhancing the reading comprehension of grade 12 students at University of Cebu Lapu-lapu and Mandaue, Mandaue City, Cebu, S.Y. 2019-2020. The findings served as the basis for a proposed seminarworkshop for English teachers. In conclusion, prediction chart is an effective strategy in improving student's reading comprehension. The chart is excellent in schemata growth as students share predictions from reading with their peers and gain new experiences.

In the light with the implications of this study, the following are hereby recommended:

1. Topics for future researches:

1.1 The use of Prediction Chart as a strategy in studying other macro-skills in English;

1.2 The use of Prediction Chart in engaging students in technical-vocational, arts and design, and sports track.

2. Adoption of the proposed seminar-workshop for teachers.

\section{References}

[1] Ajideh, P. (2003). Schema theory-based pre-reading tasks: A neglected essential in the ESL reading class. The Reading Matrix.

[2] Anderson, J. (2008). Practical English language teaching reading. McGraw-Hill companies.

[3] Bailey, E. (2015). Reading comprehension skills: making predictions.

[4] Durkin, D. (1993). Teaching them to read. 6th ed. Allyn \& Bacon.

[5] Gaither J. F. (2011). Making predictions: a strategy for reading and science learning.

[6] Izquierdo Castillo, A. \& Jiménez Bonilla, S. (2014). Building up autonomy through reading strategies. Profile Issues in Teachers Professional Development.

[7] Lumontad, N. (2014). Concept mapping as a reading comprehension tool. University of Cebu. Unpublished Master's Thesis.

[8] Magliano, J. P., Baggett, W. B., Johnson, B. K. \& Graesser, A. C. (1993). The time course of generating causal antecedent and causal consequence inferences. Discourse Processes.

[9] Nuttall, C. (1982). Teaching reading skills in a foreign language. Heinemann.

[10] Philippine Star. (2010). How do Filipino students rate in reading?.

[11] Quế, H. (2012). Improving students' reading comprehension through predicting strategy instruction: an action research at Cao Ba Quat Upper Secondary school. Development of Educational Review. 
[12] Raudenbush, D. (2019). Strategies for clarifying a prediction in reading comprehension. Leaf Group Education.

[13] Roit, M. L. (2017). Effective teaching strategies for improving reading comprehension in K-3 students.

[14] Stone, S. (2017). Observational learning. Encyclopedia Britannica Inc.

[15] Test Wise Word Association. (2006). Reading strategies.

[16] Thomas-Fair, U. C. (2005). The Power of Prediction: Using Prediction Journals to Increase Comprehension in Kindergarten. Online Submission. [17] Wager, W. W., Gagné, R. M. \& Briggs, L. J. (1992). Principles of instructional design. 4th ed.. Forth Worth, TX: Harcourt Brace Jovanovich College Publishers.

[18] Weingarten, R. (2002). English language arts curriculum resource guide. Volume II. The United Federation of Teachers.

19] Wulandari, D. et al. (2017). Improving students' reading comprehension of descriptive text by using prediction strategy. UNILA Journal of English Teaching. 